\title{
Rethinking Customer Service Training: A Curricular Solution to a Familiar Problem
}

\author{
Sharon Epps, Judith Kidd, Toni Negro, Sheridan Sayles \\ University of Maryland, College Park, MD
}

\begin{abstract}
High quality customer service is an important aim of the library experience. Its importance is evidenced by attention given to the topic in scholarly literature and academic conference proceedings. This article describes the challenging process of creating and delivering a blended customer service training curriculum to all library staff working at public service points in the University of Maryland Libraries. An online course, in-person workshops and digital badges were devised. Assessment was conducted at the end of the first year, resulting in revisions to the course.
\end{abstract}

\section{INTRODUCTION}

Over the past several years, the University of Maryland (UMD) Libraries senior leadership team, including the Dean of Libraries, has changed. Throughout the change in leadership, providing high quality customer service remained a core mission. The University of Maryland is the state's flagship university and one of the nation's preeminent public research universities. The Libraries serves more than 37,000 students, 9,000 faculty and staff, and 250 academic programs (“UMD Right Now,” 2016).

In spring 2013, the Associate Dean of Public Services formed a customer service training committee and charged members with creating a customer service training program for all staff working at public service points. The authors of this article were core members of this committee. The intent was to create a unified way of providing all public services staff with a 
baseline level of job skills and knowledge, thereby ensuring that our training of staff and subsequent delivery of good customer service was standardized across service points at all of our eight branches. This includes a unique satellite branch which provides services to faculty, staff and students enrolled at 10 of the University System of Maryland institutions.

The committee began its work by conducting a literature review and an environmental scan of comparable academic institutions and creating a template for organizing the knowledge, skills and content for the training course. This was followed by a survey of library staff and students employed in the libraries using Qualtrics to determine training preferences. Training on using Canvas, the UMD Course Management System (CMS), was scheduled for members of the task force. Development of the course content modules continued for many months, reflecting results of the task force's research, the survey, focus groups and field testers. Staff previewed the course prior to its formal launch in September 2014. What we hoped would come out of this is the recognition that the provision of good customer service enables the library to be seen as an asset to the community it serves and one that is highly valued. We recognized that if we did not deliver excellent service, our customers would seek out alternatives beyond the library, thereby giving other departments on campus a greater advantage in attracting student support and campus funding.

\section{LITERATURE REVIEW}

A review of the literature reveals that much has been written about providing high quality customer service to library users. Academic libraries only recently, since the 1990s, have begun to use the term "customer" when referring to library patrons. It was around this time that academic institutions, including libraries, became increasingly interested in customer service and Total Quality Management (TQM) issues. The introduction of TQM in academic libraries 
emphasized developing organizational cultures that focused on providing quality service and systems (Arthur, 1994). As a result, academic libraries began implementing a variety of customer-service training programs. Gwen Arthur (1994) emphasizes that customer-service training is "key" to quality service. She states:

Customer-service training includes distinctive components that help staff to understand more about service encounters, including how to positively meet customer expectations and how to deal effectively with customers in frequent and even stressful interactions. (p. 219)

In emphasizing that high quality customer service is an important value of the library profession, American Library Association (ALA) President Hardy Franklin introduced customer service as his theme in 1993, and ALA presented a national video teleconference on quality service in 1994 (Arthur, 1994). It has also been incorporated into the ALA Code of Ethics: We provide the highest level of service to all library users through appropriate and usefully organized resources; equitable service policies; equitable access; and accurate, unbiased, and courteous responses to all requests. (ALA, 2008)

Good customer service enables the library to be seen as a valued campus partner. The pressure to succeed at providing high quality customer service is greater than ever. As other service providers resort to automated interactions such as phone trees and web sites, libraries continue to offer service with a personal touch, assisted by technology, where library workers are actively engaged in serving the customer. This approach can provide the libraries with a competitive advantage (Matteson \& Boyden, 2014). 
Academic libraries have to compete with other campus departments for scarce funding and resources. High quality customer service is one of the best strategies libraries can employ to keep our customers satisfied, thereby providing support for libraries’ budget requests (Saunders, 2013).

It is also believed that good customer service is beneficial in creating job satisfaction and motivation for staff, in addition to more rewarding and less stressful work. It also promotes a greater chance for innovation and creativity as well as greater recognition for individual staff members for a job well done (Sidorko \& Woo, 2008).

Academic libraries use different methods to train their staff in customer service, including print materials such as student employee handbooks, one-on-one training at public service desks, on-site workshops, and online tutorials. Recent developments in technology have also provided libraries with training delivery mechanisms through social media, LibGuides, and course management systems. The University of Michigan recently assembled a customer service team that developed an online training module that includes a "Best Performance” workshop (McGlynn, Griffes, \& Arab, 2012). They also utilized amusing clips or photos related to each concept, group discussion between sessions, and role-playing scenarios. The University of Minnesota has also developed an online customer service training program built around their “Access Services Customer Service Philosophy” (Bayer \& Llewellyn, 2010). Their web-based project was considered a success and expanded to support a training curriculum for all staff who provide direct service to users. These institutions presented their training programs at the Access Services Conferences, in 2010 and 2012, respectively.

The UMD Libraries presented their Customer Service Training Curriculum Program at the 2014 Access Services Conference (Epps, Kidd, Negro, \& Sayles, 2014). Ippoliti (2014) 
discusses the planning and implementation of the Customer Service Training curriculum at UMD. The author gives a detailed summary of the Customer Service Committee's work and process of determining training needs and creation of the training curriculum for Public Services staff. The provision of high quality customer service continues to be an important issue for academic libraries as evidenced by presentations (Hargett, 2015; McInerney, Mlady, \& Rodrigues, 2015) on this topic at the 2015 Access Services Conference.

Other libraries such as The Ohio State University Libraries (Lowry, 2016), University of Pennsylvania (Drake \& Martin, 2016), and Wayne State University (Wayne State University Libraries, n.d.) have developed LibGuides to deliver training to their staff.

Whatever methods are used, in order for customer service training to be effective, there also needs to be assessment and support for successful application of skills after the training (Arthur, 1994). According to Wilkinson and Lewis (2006), "library administrators must believe in and support training” (p.358) in order for it to be successful. The authors stressed, "They must communicate the importance of training through their words and actions at all levels of the organization-they must 'walk the talk”' (p. 358). The long-term effects of customer service training on a large organization cannot be understated. It is a gradual change and will only be successful with sustained effort and consistent attention (Jennerich, 2006).

\section{STAFF BUY-IN}

Staff buy-in was extremely important to the success of the training program. We set out to get buy-in by providing opportunities for staff to play an active role in the development of the training program. Staff forums established a shared customer service philosophy and vision and determined our top service standards and values. We also conducted a survey of public services staff and convened stakeholder meetings in order to find out what type of training was needed, 
what is currently being provided, and to identify the gaps. Everyone agreed that providing a variety of training formats would be best to accommodate various learning styles and needs.

Based on the findings, the committee recommended creating a course in Canvas, with a certificate of completion provided at the end of the course. As developed over the next few months, the course consists of pages of text, web pages, videos, PowerPoint presentations, and interactive maps. The course can be updated on a regular basis. Individual staff progress with the course can be tracked, and outcomes can be measured and assessed. Another important feature of the course is that it can be accessed 24/7, thus providing staff with ease of access to participate in the training program.

\section{COURSE CONTENT}

The course was shaped by the committee final report, which concluded that the most valuable materials for staff to be well-versed in were: communication, job skills, and job knowledge. Since employees from eight different branch libraries are required to take the course, all course content relates to campus-wide policies and information, and the committee decided that branchspecific details would be explained in training with the staff's supervisors. Staff are given one academic year to complete the course.

The first portion of the course focuses on the verbal, non-verbal, and situational modes of communication that staff members encounter with customers and other employees at the University. This section shows best practices for communication both in-person and online, giving staff a holistic overview of the different ways that subtle cues can add up. Course enrollees work through a mix of suggestions and examples to see what the best approaches look like in practice. 
The next part, Job Knowledge, shows staff the information they would need to become both acquainted with the University and with their jobs. This module gives a detailed overview of the campus, campus policies, and general libraries policies. This portion of the course is instrumental for staff who work in public service points, since directional and policy-related assistance are among the most prominent services that the Libraries offer. To provide an authentic experience, the course supplements its content with real-world scenarios.

The final portion of the course is the Job Skills section, which guides staff through the technological and procedural aspects of good customer service. This section provides staff with an overview of the tasks associated with the policies and gives them enough information to perform each duty. While not all staff ordinarily have to use all of the knowledge and skills discussed in the course-in some branches, for example, only circulation staff may need to perform basic inter-library loan procedures_-the committee felt that knowing how to do these procedures, regardless of an individual staff member’s duties, would allow him or her to substitute in an emergency, or at the very least to better explain the library's workings to patrons.

\section{COURSE FORMAT}

The course consists of four modules that introduced the course and touched on each of the three previously mentioned sections. Each module featured a mixture of information and real-life scenarios in which a staff member could use this information. The format for each module varies according to the nature of the material. Procedural information, for example, is provided through video or PowerPoint presentations, and policies are delivered in a textual format. Content is intended to be concise, so that employees could quickly refer back to the course if needed. 
Each module culminates in a short quiz that contained between three and seven questions that were worth 5 points apiece. Each quiz contains a mix of multiple choice and short answer questions that were designed to test whether employees could recall basic facts about policies and procedures, such as the length of a checkout period, and also test their ability to use information in particular situations, like how to diffuse a conflict. Staff needed to score $80 \%$ or better on each quiz in order to pass the course. Participants could retake the quiz and did not require supervisor approval in order to do so.

The customer service working group felt that the course would need to have a partially blended approach in order for it to fully support staff learning. The online course was designed to function independently, so staff could complete the customer service training with the online course alone. The group had designed the in-person workshops to be supplemental practice that related to the content of the course, so that staff members could get face-to-face experience with the interpersonal aspects of the course and also gain insight into topics that were not wellcovered in the online component. Topics discussed in the in-person sessions included diversity and inclusive language and conflict management.

\section{CREATING THE ONLINE COURSE}

The customer service working group created course module content over a 6 month period. The UMD Libraries' website was a major source of information, and ensuring that staff were knowledgeable of all aspects of the website was one of the intended outcomes of the course. Short videos were created to illustrate such subjects as the use of common software, issuing/returning interlibrary loan materials, and basic service point tasks, in order to accommodate staff with different learning styles. These were backed up by written instructions 
in a simple, straightforward style. In addition, all videos were given subtitles for ADA compliance (Figure 1).

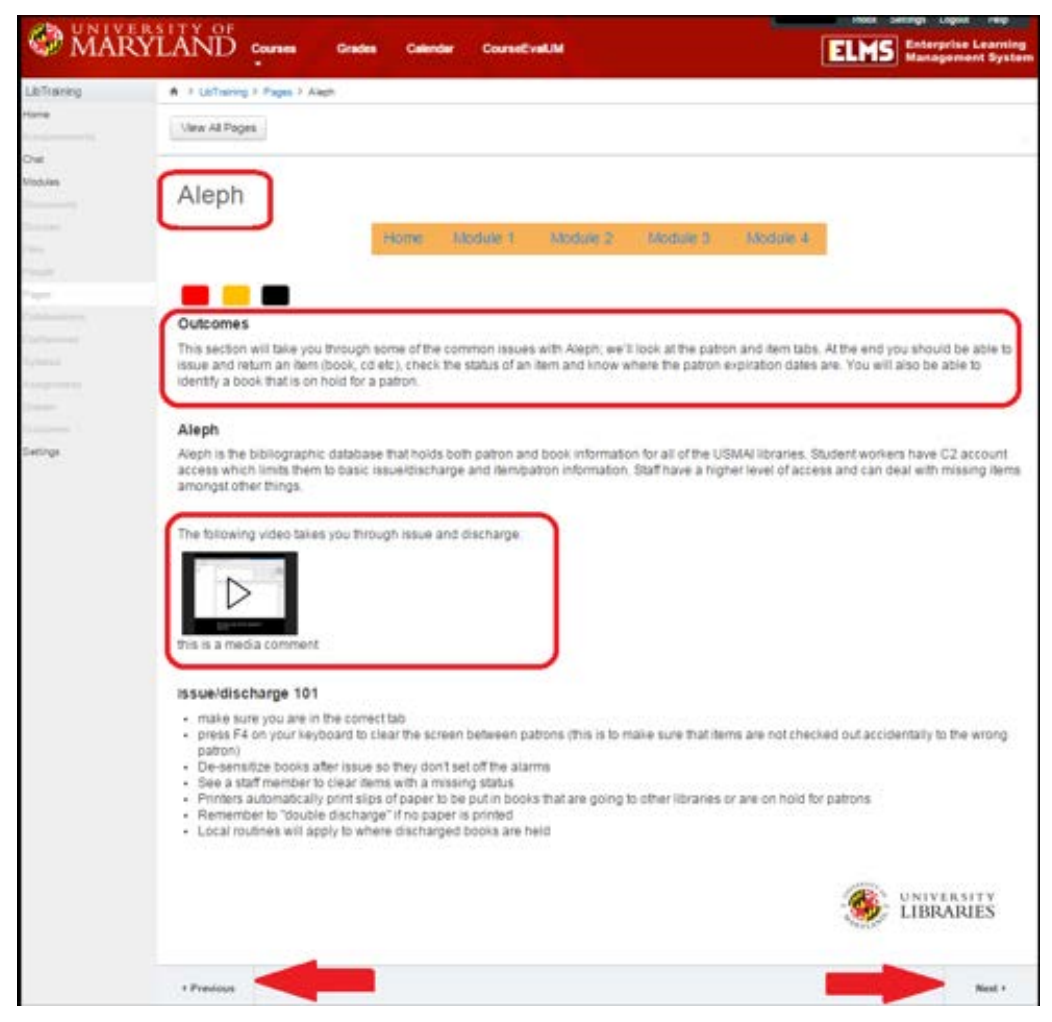

Figure 1. Screenshot showing intended outcomes for an individual lesson, link to video content and a summary 101 style.

Once the initial content had been created and uploaded to Canvas, it was tested by volunteers. Spelling, punctuation and broken hyperlinks were easily fixed. However, more significant problems with navigation and consistency also emerged. Users could not find their way around the site and had no overall view of the content. A librarian with extensive experience with using both Canvas and creating online classes demonstrated the need for a navigation bar on each page, hyperlinks to course content, and a table of contents (Figure 2). 


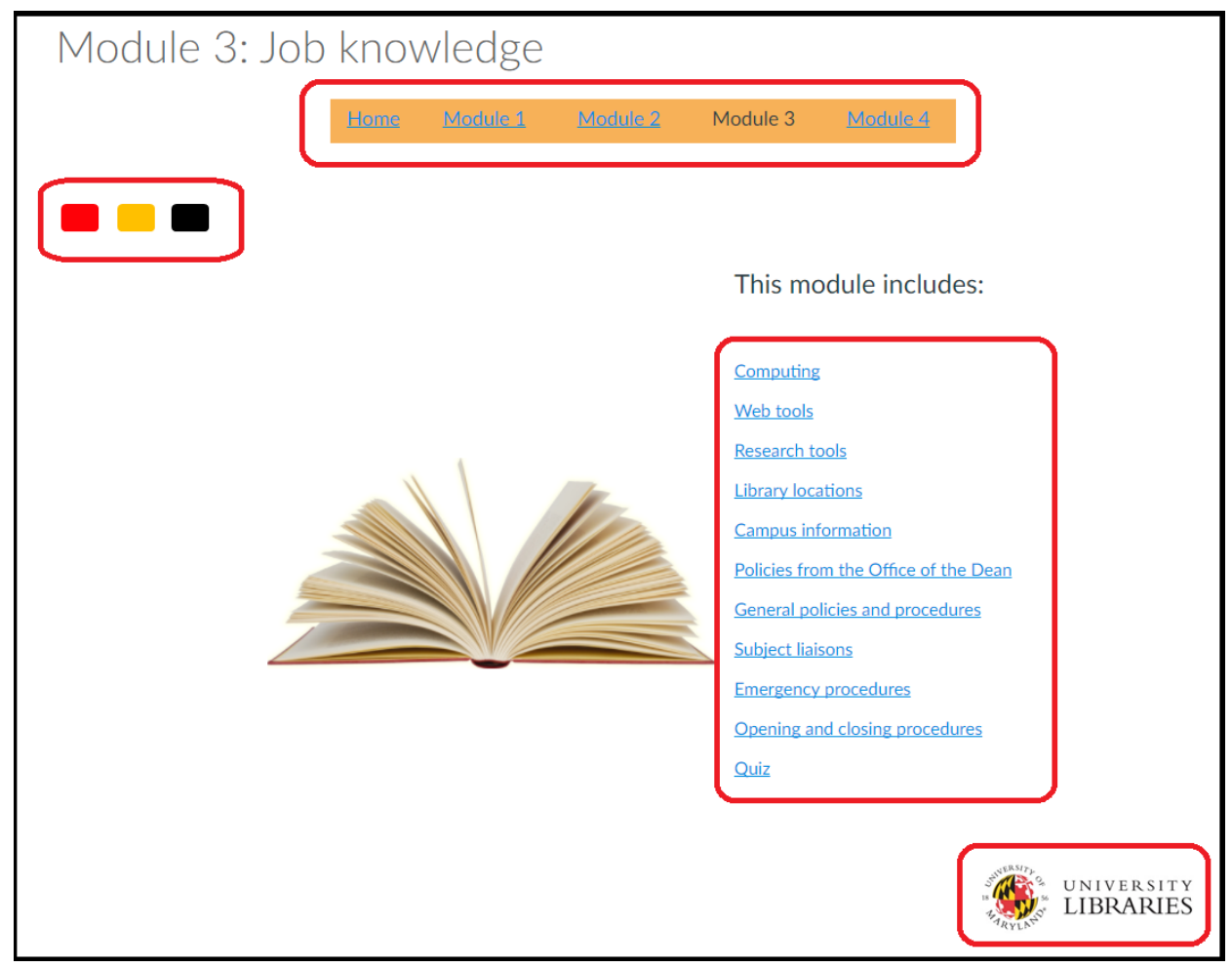

Figure 2. Screenshot of "Module 3: Job knowledge” contents page. The color band and navigation bar are at the top of the screen; the UMD Libraries logo is at the bottom right (included on every course page). A hyperlinked contents list provides both access to the course and course over-view.

Branding the course using UMD colors, logo and photographs was important, and we worked with the Libraries' Director of Communications to follow branding standards at the University. Additionally, we realized that users would inevitably compare the course to more sophisticated online resources. While we did not have the technical support to compete with professionally designed and supported websites, the CST course needed to be clear, well planned, and executed.

Following the addition of branding elements and navigation buttons, another round of testing took place. Student volunteers were asked to check for hyperlinks and internal course 
links. This resulted in the discovery of another problem with navigation: when rearranging the order of modules and other sub-parts of the course, some navigational hyperlinks were either broken or misdirected the user. Once this issue had been identified and fixed, the course was ready for launch.

\section{INSTRUCTION FOR USERS}

Two documents were written to support users of the course: a user guide for staff and student workers and a guide for supervisors. The user guide for staff and student workers was written to accommodate both undergraduates with extensive experience of Canvas through their regular courses as well as staff unfamiliar with this platform. In addition, as the course was intended to be completed during work time, the guides provide assistance for branch libraries and is accessible at any time. Specific topics include help with on logging on and using Lynda.com, the UMD-wide online learning platform, as well as step-by-step instructions for completing the course.

While the Supervisor guide provides much of the same information as the staff/student guide, it also contains back-end information to comply with the course policies. It includes details about enrolling people in the course, grading quizzes by using the rubrics, and reporting successful completions of the course to the CST team so that digital badges could be issued.

\section{EVALUATION OF PROGRAM}

Staff were given the academic year 2014-15 to complete this course, and the CST team held a forum in May 2015 to discuss outcomes. At that time, approximately 160 staff and students worked in the Public Services Division (PSD), of whom 136 had been registered for the course 
by their supervisors. Their level of participation is detailed in Table 1. In all, 88 staff and student workers spent time on the site, and 13 completed the course and were awarded digital badges.

\begin{tabular}{|l|l|}
\hline Activity & Number of people \\
\hline Did not accept invitation & 19 \\
\hline Accepted invitation but no activity & 29 \\
\hline 0.01 to 0.59 hours & 26 \\
\hline 1 to 4.59 hours & 37 \\
\hline 5 to 9.59 hours & 12 \\
\hline More than 10 hours & 13 (includes 4 course creators) \\
\hline Total & $\mathbf{1 3 6}$ \\
\hline
\end{tabular}

Table 1: Chart showing level of participation in the University of Maryland Libraries Customer Services Training Canvas course, May 2015.

Seventeen staff attended the May 2015 forum, including staff from branches and the main library, student supervisors and line managers of staff. Several issues emerged from this forum:

- There was a lack of clarity as to who should complete the course and who would enforce/encourage participation. There had been no strategy for completion requirements.

- Supervisors reported logistical problems in running the course e.g. adding staff and grading questions. Many quizzes were deemed to be too simplistic or unnecessary, while questions needing supervisor grading using rubrics were felt to be too cumbersome. However, one student supervisor felt written responses to the communication module were useful as they showed "what student workers were thinking".

- The digital badge was not seen as a meaningful reward for completing the course.

- There was too much content. The course took too long to complete and contained links that needed frequent updating. The Job Skills module was regarded as unnecessary because the content was covered in person by local-unit supervisor training. 
The CST team analyzed the results of the forum and, in consultation with the Associate Dean for Public Services, decided to address concerns by:

- Agreeing that the Associate Dean of Public Services should consult his managers regarding who should complete the course and thereby create a completion strategy.

- Greatly reducing the number of quizzes.

- Discontinuing the digital badge.

- Deleting Module Four - Job Skills and cutting content in Module Three - Job Knowledge.

Implementing these changes involved careful planning so that content would not be lost. A parallel course was created and content was added. We feared that editing the original course risked losing content. An introductory video by the new Dean of Libraries has been added. Navigation and links were checked before the course was handed over to the Associate Dean of Public Services.

\section{LESSONS LEARNED}

The survey distributed to library staff before development of the customer service training program found differing perceptions of what customer service is and differing preferences for training. The highest need for training included addressing basic policies, basic technologies and e-etiquette, and handling emergency situations. Preferences for training ranged from independent study and online tutorials to in-person workshops, role playing and hands-on experiences. It was important to have a variety of methods to accommodate varied learning styles and needs. The lesson learned was to start the course development with a pre-assessment of user experience or perceptions of customer service. 
Barriers to implementation of the customer service training course were identified early as time constraints, problems with scheduling at point of need, inconsistency and unequal access to content, and lack of supervisor support for training. Focus groups with librarians, library staff and student assistants met with the planning committee. Respondents indicated a high priority for having regular meetings to discuss customer service issues, knowing administrative expectations for skills and values needed for customer service, and the creation of shared learning experiences to measure successes and areas of weakness. Regular progress reports made on LIBI, the UMD Libraries intranet site, and to representative staff groups such as the Library Assembly and Library Management Group became essential to ensure acceptance of the course.

Field testers were engaged as the course reached its completion, and adjustments were made before launching the course. This period identified several problems related to consistency and equal access. It was important to users that all content be consistently available throughout the time allotted for completion of the course. Field testing alongside the development of the course would have resulted in early identification of problems and minimized the need to make later changes.

In an effort to have a variety of formats and meet different learning styles, the use of media and website links created unanticipated challenges with their inclusion in the course management system. Links to videos, webpages and embedded programs needed to be stable and available throughout the time frame allotted for completion of the course. Access to all content had to be available since course modules could be completed at the employee's convenience and at their library locations. Even the technical abilities of those taking the course had to be taken into account, as some users struggled with the technical component. 


\section{CONCLUSION}

At the end of the academic year 2014-15, responsibility for the online customer training course was transferred to the Associate Dean of Public Services with a brief report containing analysis of data and forum results. The CST indicated that the charge to the committee had been completed. The course had been developed, implemented and revised based on staff recommendations, data analysis of respondents, and quizzes and comments from individuals who completed the course.

The CST recommended that a second team be appointed to revise the online course incorporating results of the data analysis, staff forum, and lessons learned from the implementation of the course. The team continues to recognize the value of customer service training for public access staff that reflects the needs and preferences of staff, with easy access and stable functionality. The course also needs to account for the diversity of services and patrons on a campus with multiple branches.

The major issues to address for improvement of the course include expanded committee representation, especially technical and library support staff, frequent communication with supervisory and administrative staff, and continuous monitoring of navigation and relevant assessment tools. In addition to content, implementation of the course needs to consider local library staff needs and their local library environments. 


\section{REFERENCES}

About the University of Maryland. (2016, May). University of Maryland. Retrieved from http://umdrightnow.umd.edu/about-university-maryland

Arthur, G. (1994). Customer-Service Training in Academic Libraries. The Journal of Academic Librarianship, 20(4), 219-222.

Bayer, J, \& Llewellyn, S. (2010). The Customer Comes First: Implementing a Customer Service Program at the University of Minnesota, Twin Cities Libraries [Presentation]. Paper presented at the 2010 Access Services Conference. Atlanta, GA. Retrieved from http://hdl.handle.net/1853/36636

Code of Ethics of the American Library Association. (2008). American Library Association. Retrieved from http://www.ala.org/advocacy/proethics/codeofethics/codeethics

Drake, R. \& Martin, E. (2016, May). Penn Libraries Student Employment Guidelines and Customer Service Training. Penn Libraries. Retrieved from http://guides.library.upenn.edu/studenttraining

Epps, S., Kidd, J., Negro, A., \& Sayles, S. (2016, May). Re-thinking Customer Service Training: A Curricular Solution to a Familiar Problem [Presentation]. Paper presented at the 2014 Access Services Conference. Atlanta, GA. Retrieved from http://hdl.handle.net/1853/53128

Guide to Student Assistant Success: Customer Service. (2016, May). Wayne State University Libraries. Retrieved from http://guides.lib.wayne.edu/studentacademy

Ippoliti, C. (2014). Are You Being Served? Designing the Customer Service Curriculum. Public Services Quarterly, 10, 177-192. DOI: 10.1080/15228959.2014.914864

Jennerich, E. (2006). The Long-Term View of Library Staff Development: The Positive Effects on a Large Organization. College \& Research Libraries News, 67(10), 612-614.

Lowry, C. (2016, May). The Student Assistant Training Program. The Ohio State University Libraries. Retrieved from https://library.osu.edu/about/departments/teachinglearning/student-assistant-training-program/

Matteson, M. \& Boyden, C. (2014). Old Wine in a New Bottle: Customer Orientation in Librarianship. Reference Services Review, 42(3), 433-445. Retrieved from http://dx.doi.org/10.1108/RSR-02-2014-0003

McGlynn, M., Griffes, S., \& Arab, S. (2016, May). Training for Service [Presentation]. Paper presented at the 2012 Access Services Conference. Atlanta, GA. Retrieved from http://hdl.handle.net/1853/46168 
Saunders, L. (2013). Learning from Our Mistakes: Reflections on Customer Service and How to Improve It at the Reference Desk. College \& Undergraduate Libraries, 20, 144-155.

DOI: $10.1080 / 10691316.2013 .789661$

Sidorko, P., \& Woo, E. (2008). Enhancing the User Experience: Promoting a Service Culture Through Customized Staff Training. Library Management, 29(8-9), 641-656. Retrieved from http://dx.doi.org/10.1108/01435120810917279

Wilkinson, F., \& Lewis, L. (2006). Training Programs in Academic Libraries: Continuous Learning in the Information Age. College \& Research Libraries News, 67(6), 356-8, 365. 